\title{
Outsourcing Peter to Pay Paul: \\ High Skill Expectations and Low-Skill Wages with Imperfect Labor Markets
}

\author{
Carl Davidson $^{\text {a,b }}$, Steven J. Matusz ${ }^{a, b}$, and Andrei Shevchenko ${ }^{a}$ \\ ${ }^{\text {a }}$ Department of Economics, Michigan State University, East Lansing, MI 48824 \\ ${ }^{b}$ GEP, University of Nottingham
}

\begin{abstract}
In this paper we investigate the impact of globalization on wages earned by low and high-skill workers when openness leads to the outsourcing of high-tech jobs abroad. We have show that low-skill workers may become considerably better off after globalization due to the fact that high-skill workers start accepting low-tech jobs. The switch in the behavior of high-skill workers brings about general equilibrium responses from the firm side of the labor market with the outside options for low-skill workers improving significantly. This feedback works as a magnification mechanism that leads to a discontinuous wage increase that one would not be able to get without careful modeling frictions in the labor market.
\end{abstract}




\section{Introduction}

Over the past few decades many American companies have faced growing economic incentives to move certain productive activities abroad. Technological advances, improvements in telecommunications, and trade deregulation have made it very attractive to move some stages of the production process to foreign countries where labor can be hired at relatively low cost. Over the past few years, new concerns have arisen as firms have begun to outsource services that were typically performed by relatively high-skilled workers in the United States. The New York Times and other major publications have been filled with stories of computer companies staffing their call centers with workers located in foreign countries and hospitals sending their x-rays to be read by doctors overseas. The concern seems to be that now even high-skilled workers are losing their jobs to foreign competition and that this is a major problem because these are the very jobs that are the most desirable to keep.

Economists have responded to such concerns in a variety of ways. We have pointed out that the total number of jobs actually outsourced is rather small relative to production and employment, (see, for example, a discussion pertaining to the U.S. economy in Bhagwati, Panagariya and Srinivasan 2004) and that the process of outsourcing makes manufacturing firms more viable, leading to greater domestic job creation with the net effect on employment being positive (Slaughter 2004). However, many in the policy community remain skeptical that concerns about outsourcing can be dismissed so easily and point out that even though the size of the relocation activities is rather small now, there is no doubt that in future these numbers will increase significantly. As a result, the impact of outsourcing on income distribution and living standards has become a major concern for the general public and policymakers. While there are long-held concerns that import competition from low-wage countries creates pressure on low- 
skill wages in manufacturing, the current concern seems to be that the outsourcing of high-tech services will reinforce the increase in income inequality.

The purpose of this paper is to investigate the impact of high-skill outsourcing on wages with a particular emphasis on its effect on low-skill wages. Our emphasis on the impact on lowskill workers follows from concerns that these workers are often hit the hardest by trade liberalization in industrialized economies. To investigate this issue, we think that it is essential to use a framework that captures many of the key features of the job dislocation process, as reported by Jacobson, LaLonde and Sullivan (1993) and Kletzer (2001). In particular, we want to use a model in which high-skill workers, dislocated due to outsourcing, suffer non-trivial spells of unemployment before eventually finding a new job at a lower wage. Evidence suggests that these wage losses may be substantial, especially for older workers. For example, Jacobson, LaLonde and Sullivan (1993) estimate that the average loss in lifetime earnings for a dislocated worker is roughly $\$ 80,000$ with the bulk of this loss attributed to a reduction in the reemployment wage.

We also want to use a framework that captures one of the essential features of American manufacturing industries, as report by Doms, Dunne and Troske (1997), which is that firms make heterogeneous technology choices with those using the more advanced technologies employing workers with higher skills and paying higher wages. Thus, we want a model in which workers differ in terms of their skills and firms endogenously choose to adopt technologies of different levels of sophistication. This results in a setting in which we have heterogeneity on both sides of the labor market.

We developed a model with these features in Davidson, Matusz and Shevchenko (2005), by adopting a framework first suggested by Albrecht and Vroman (2002). The basic idea behind the model is really rather simple. There are two types of workers, high and low skilled, that must 
search for employment across firms that have chosen to adopt different technologies. The firms' technology choices are endogenous, with all firms starting out ex ante identical. Those that choose the less sophisticated option, the "basic technology," can produce output using either high or low skilled labor and pay their workers relatively low wages. That is, for low-tech firms, high and low skilled workers are perfect substitutes in the production process. Firms that adopt the more sophisticated option, the "modern technology," can only produce output using high skilled workers and must pay these workers relatively high wages. However, the fact that these workers are using a more sophisticated technology implies that they will be more productive than if they had been employed by a low-tech firm.

When firms enter the market, they must first make their irreversible technology decision and then post a vacancy which will be filled as workers apply for the position. Entry occurs until the expected profit from posting a vacancy is driven to zero for both types of firms. Note that the two types of firms can co-exist in equilibrium since the low-tech firms pay lower wages but employ less productive workers.

The most intriguing feature of this model is that for a wide variety of parameter values, two types of equilibria co-exist. In one type of equilibrium, high-skill workers refuse to accept jobs at low-tech firms. Albrecht and Vroman refer to this as an "ex-post segmentation" (EPS) equilibrium since the market effectively separates with low-tech firms employing only low-skill workers and high-tech firms employing only high-skill workers. In the other type of equilibrium high-skill workers accept the first job offered to them. In this "cross-skill matching" equilibrium, the low-tech firms can afford to pay high-skill workers enough to entice them to stop searching before finding a high-tech job.

The type of equilibrium which emerges depends to a large extent on the labor market expectations of the high-skill workers. If these workers expect it to be relatively easy to find a 
high-tech job, they will refuse to accept low-tech jobs. This makes it harder for low-tech firms and easier for high tech firms to fill their vacancies and leads to an equilibrium in which a greater proportion of firms choose to adopt the more sophisticated technology. As a result, the highskilled workers expectations that high-tech jobs will be easy to find are fulfilled.

Things are exactly reversed in the CSM equilibrium: High-skill workers take low-tech jobs because they expect high-tech jobs to be relatively hard to find. These expectations are then self-fulfilling as their willingness to accept such jobs leads to a greater proportion of firms adopting the less sophisticated technology. The implication is that the main differences between the two types of equilibria are the expectations of the high skilled workers and the proportion of firms that adopt the two types of technologies.

To investigate the impact of high-skill outsourcing on wages we assume that firms are initially constrained to hire only domestic workers. We assume further that unemployed high skill workers are optimistic about the chances of finding high-tech jobs, so that the initial equilibrium is of the EPS variety. Globalization then makes it possible for high-tech firms to find and employ high-skill foreign labor at a cost below the cost of searching for and employing domestic high-skill workers. In the short run, when new firms have not yet entered the market, some high-tech firms start to outsource their jobs. As fewer high-tech jobs are available for domestic high-skill workers, the domestic wage earned by these workers falls. Domestic highskilled workers, now facing lower high-tech job opportunities and lower high tech wages, start to accept low-tech jobs. In other words, in the short-run outsourcing destroys the viability of the ex post segmentation equilibrium. The economy therefore moves to the cross-skill matching equilibrium. High-skill workers lose, since they see their wages eroded by outsourcing. Lowskill workers also lose, since they faced increased competition for low-tech jobs from their high- 
skill counterparts. Firms are the only winners, now earning higher profits due to their ability to outsource and the across-the-board reduction in wages.

In the long run, these short run profits induce new entry. As new firms enter, they make their technology choice based on the expectations of the high-skilled workers. If the high-skill workers who were dislocated by outsourcing in the short run continue to expect difficulty finding high-tech jobs (a reasonable assumption based on their most recent labor market experiences) then the economy will stay in the CSM equilibrium. And, since this CSM equilibrium is characterized by a greater proportion of firms using the less sophisticated technology than in the original (pre-globalization) EPS equilibrium, this new long run equilibrium is relatively more attractive for the low-skilled workers. In particular, once sufficient entry has occurred (particularly by low-tech firms), the low skill workers find it easier to find employment and earn higher wages than they did in the initial long run equilibrium. Thus, our main finding is that, under certain conditions, the outsourcing of high-skill jobs in a particular industry is likely to lead to wage gains for low-skill workers in that same industry. Note that this result follows directly from the impact of outsourcing on the labor-market expectations of high-skill workers and the role these expectations play in shaping the structure of the industry.

After discussing the impact of high-skill outsourcing on wages, we go on to investigate its welfare implications. We find that when outsourcing alters the expectations of high-skill workers, globalization can lead to aggregate welfare losses. However, if the government offers trade adjustment assistance (TAA) to workers dislocated by globalization, such welfare losses can be averted. The reason for this is straightforward - TAA is effectively an increase in unemployment benefits, which lowers the cost of remaining unemployed for dislocated workers. Thus, by increasing unemployment benefits in the short run, the government can keep high-skill workers from accepting low-tech jobs and can ensure that their expectations do not change in a 
way that destroys the viability of the EPS equilibrium. These additional benefits can then be phased out in the long run as new high-tech firms enter the market to replace those that have engaged in outsourcing.

The remainder of the paper divides into four sections. In the next section, we describe the model when firms are constrained to employ only domestic workers; and, in section 3 we extend the model to allow for outsourcing by high-tech firms. In section 4 , we describe the short and long run adjustment in wages and profits to high-skill outsourcing. We discuss the policy implications of our results in the concluding section.

\section{The Model without Outsourcing}

We use a two-country version of the model developed in Davidson, Matusz and Shevchenko (2005) which in its turn is a straightforward extension of Albrecht and Vroman (2002). We refer to the more developed country as the North (N) and the less developed country as the South (S). In each country, there are two types of workers: low-skilled and high-skilled, with the proportion of the workforce that is high-skilled varying across the two countries. In particular, we assume that both countries are characterized by a continuum of risk neutral workers of measure 1 with $q_{i}$ denoting the fraction of workers in country $i$ that are low-skilled.

By assumption, the North has a more productive labor force than the South in that $q_{N}<q_{S}$. In addition, we assume that firms in the North have access to two technologies: a basic (or lowtech) technology and a modern (or high-tech) technology; whereas firms in the South can only use the basic technology.

Our objective is to investigate the impact of high-skill outsourcing by Northern firms on Northern wages when labor markets are imperfect. This is accomplished by first assuming that Northern firms can only hire Northern workers. We then compare this outcome with the 
equilibrium that emerges when Northern high-tech firms can outsource production by hiring high-skilled Southern workers. In this section, we describe the model without outsourcing. Since the South plays no role in determining the Northern wages when outsourcing is not possible, we delay further discussion of the activities in the South until the next section.

Because workers differ by skill and Northern firms differ in the technologies that they adopt, the labor market in the North is characterized by heterogeneity on both sides of the market. The imperfection in the labor market is assumed to be generated by trading frictions that make it costly for unemployed workers and firms with vacancies to meet. This allows us to model the search process that dislocated workers in the North must go through in order to find reemployment after their jobs have been outsourced. Although some firms may use different technologies, we assume that all firms produce the identical product which is then exported to a competitive world market. Both countries are assumed to be small, so that the price of this product is fixed exogenously at the world price and labor, which is the only input, is sector specific in both countries. The world price is normalized to 1 .

As noted above, in this section we assume that, due to prohibitive costs associated with outsourcing, Northern firms employ only Northern workers. Each Northern firm that chooses to adopt the low-tech technology produces $y_{L}$ units of output whenever its vacancy is filled regardless of the type of worker they hire. That is, for low-tech firms, high and low skill workers are perfect substitutes in production. A Northern firm that adopts the high-tech technology can only produce by hiring a high-skill worker and when their vacancy is filled they produce $y_{H}>y_{L}$ units of output. ${ }^{1}$ Note that each firm employs at most one worker.

\footnotetext{
${ }^{1}$ One can make more general technological assumptions allowing for both types of workers to perform any type of job with high-skill workers being more productive than low-skill ones. This would make presentation less tractable without adding new insights to the paper.
} 
When a Northern firm first enters the market, it must commit to a technology and then post a vacancy. The flow cost of creating and maintaining a vacancy is $c$, regardless of which type of technology is adopted. After the risk neutral firms post vacancies, unemployed workers and firms with vacancies are randomly matched. Once these two are matched, the firm reveals its technology choice to the worker. If the firm decides to hire the worker and the worker is interested in the job, the two agents then negotiate a wage rate with the outcome given by the Generalized Nash Bargaining Solution. The matching function is given by $m(u, v)$ where $u$ denotes unemployment and $v$ denotes vacancies. We assume that $m(u, v)$ is characterized by constant returns to scale and define $\theta \equiv \frac{v}{u}$ as our measure of market tightness. Then, with random matching, the arrival rate of vacancies for a typical worker is given by $m(\theta)$; whereas the arrival rate of workers for a typical firm is given by $z(\theta) \equiv m(\theta) / \theta$. Following Albrecht and Vroman (2002) we assume that $m^{\prime}(\theta)>0$ and that $z^{\prime}(\theta)<0$. Finally, we assume that jobs are destroyed at rate $\delta^{2}$

Albrecht and Vroman (2002) demonstrate that there are two types of equilibria in this model. Using Albrecht and Vroman's terminology, the economy is characterized by a "CrossSkill-Matching Equilibrium" (CSM) if high-skill workers are willing to accept low-tech jobs. In contrast, the economy is characterized by an "Ex-Post Segmentation Equilibrium" (EPS) if highskill workers refuse jobs at low-tech firms. A CSM typically exists if the wages that high-skill workers can expect to earn on the two types of jobs are not too different. Thus, the type of equilibrium that exists depends upon parameter values and the expectations of the high-skilled workers. At most, there can be only one CSM equilibrium and one EPS equilibrium. For some parameterizations, the two types of equilibria co-exist, whereas in other cases, the market

\footnotetext{
${ }^{2}$ Of course, the job will also be destroyed if either party decides to voluntarily dissolve the match. This approach to
} modeling the labor market is due to Pissarides (2000) and Mortensen and Pissarides (1994). 
equilibrium is unique. We provide more details on this issue below, but for now we assume that a cross-skill matching equilibrium exists. This means that high-skilled workers accept any job that is offered to them.

Under this assumption, the value functions for the firms' problem can be written as

$$
\begin{aligned}
& r J_{i}=\left\{y_{i}-w_{i}-c\right\}-\delta\left[J_{i}-V_{i}\right] \quad \text { for } i=L, H \\
& r J_{U}=\left\{y_{L}-w_{U}-c\right\}-\delta\left[J_{U}-V_{L}\right] \\
& r V_{L}=-c+z(\theta)\left\{\gamma J_{L}+(1-\gamma) J_{U}-V_{L}\right\} \\
& r V_{H}=-c+z(\theta)(1-\gamma)\left[J_{H}-V_{H}\right]
\end{aligned}
$$

where $J_{i}$ for $i=L, H$, is the value function for an active low or high-tech Northern firm that employs a low or high-skill worker correspondingly; $J_{U}$ is the value function of an active Northern low-tech firm that employs a high-skill worker; ${ }^{3}$ and $V_{i}$ for $i=L, H$ is the value of an unmatched low or high-tech Northern firm. In (1)-(4) we also use $w_{i}$ with $i=L, H$ to denote the wage a low or high-tech Northern firm pays to its low or high-skill worker correspondingly; $w_{U}$ to denote the wage paid by a low-tech Northern firm to a high-skill worker; $r$ to denote the discount rate; and $\gamma$ to denote the fraction of low-skill workers in the unemployment pool.

In (1)-(4), the first term on the right-hand-side is the flow income earned by the firm. So, for example, an active type $i$ Northern firm earns a flow profit of $y_{i}-w_{i}-c$ when it sells its output; whereas a firm with a type $i$ vacancy earns no revenue and incurs a flow cost of $c$ to maintain its vacancy. The second term on the right-hand-side is the firm's expected capital gain (or loss) from changing its labor market status. For example, an active type $i$ Northern firm loses its worker at rate $\delta$ and when this occurs the firms expected lifetime profits drop from $J_{i}$

\footnotetext{
${ }^{3}$ The sub-script $U$ stands for underemployed.
} 
to $V_{i}$. On the other hand, low-tech Northern firms fill their vacancy at rate $z(\theta)$ and their expected lifetime profit jumps to $J_{L}$ if they match with a low-skill worker (which happens with probability $\gamma$ ) or $J_{U}$ if they match with a high-skill worker. Note that a high-tech Northern firm fills its vacancy at a lower rate of $(1-\gamma) z(\theta)$ since it can only employ high-skill workers.

As we noted above, wages are negotiated by the firm and its worker with the solution given by the Generalized Nash Bargaining Solution. If we use $\beta$ to denote the bargaining power of the workers and use $U_{i}$ to denote the expected lifetime income of an unemployed worker with skill level $i$, then Albrecht and Vroman show that the wages are given by

$$
\begin{aligned}
& w_{i}=\beta\left(y_{i}-c\right)+(1-\beta) r U_{i} \quad \text { for } \quad i=L, H \\
& w_{U}=\beta\left(y_{L}-c\right)+(1-\beta) r U_{H}
\end{aligned}
$$

Note (5)-(6) implies that although high and low skill workers are perfect substitutes in production for low-tech firms, these workers do not receive the same wages in the North. In particular, since high-skill workers have better outside options, low-tech firms must pay them higher wages then they would pay to low-skill workers. Thus, in general, $w_{U}>w_{L}$. This implies that Northern low-tech firms prefer to hire low-skill workers.

We assume that in the long-run there is free entry into the market. This implies that firms enter until the expected return from creating a type $i$ vacancy is zero; or,

(7) $\quad V_{L}=V_{H}=0$

We are now ready to analyze the worker's problem. Let $W_{j}$ denote the expected lifetime income for a worker with skill level $j$ who is employed by a type $j$ firm (with $j=L, H$ ) and let $W_{U}$ denote the expected lifetime income for a high-skill Northern worker who is employed by a low-tech firm. Then, using $\phi$ to denote the fraction of vacancies posted by low-tech firms in the 
North and $b_{N}$ to denote unemployment benefits, we have the following value functions for the workers

$$
\begin{aligned}
& r U_{L}=b_{N}+\phi m(\theta)\left[W_{L}-U_{L}\right] \\
& r U_{H}=b_{N}+m(\theta)\left[\phi W_{U}+(1-\phi) W_{H}-U_{H}\right] \\
& r W_{j}=w_{j}-\delta\left(W_{j}-U_{j}\right) \quad \text { for } j=L, H \\
& r W_{U}=w_{U}-\delta\left(W_{U}-U_{H}\right)
\end{aligned}
$$

As with the firms, the right-hand-side is the sum of flow income and the expected capital gain (or loss) from changing labor market status. For unemployed workers, flow income is $b_{N}$, whereas employed workers collect wages. In (8)-(9), note that the job acquisition rate for a highskill worker is $m(\theta)$ (since high-skill workers accept all jobs), whereas it is $\phi m(\theta)$ for low-skill workers (since they are only offered low-tech jobs). Moreover, an unemployed high-skill worker in the North matches with a low-tech firm with probability $\phi m(\theta)$, in which case the capital gain is $W_{U}-U_{H}$; otherwise, she matches with a high-tech firm and gains $W_{H}-U_{H}$.

In equilibrium, high-skill workers will only be willing to accept low-tech jobs if

$$
y_{L}-c-r U_{H}>0 \text {; }
$$

that is, if such a match creates positive surplus. Thus, this is the key condition that must be met for a CSM equilibrium to exist.

The remaining equilibrium conditions guarantee that we are in a steady-state by ensuring that the flows into and out of each employment state are equal. For low-skilled workers this condition is given by

$$
\delta E_{L}=\left(q-E_{L}\right) \phi m(\theta),
$$


where $E_{L} \equiv q-\eta$ denotes low-skill employment. The analogous condition that must hold for high-skilled labor is

$$
\delta E_{H}=\left(1-q-E_{H}\right) m(\theta)
$$

Where $E_{H} \equiv 1-q-(1-\gamma) u$ denotes high-skill employment and where $u$ is the measure of unemployment. In (13) and (14), the flow into unemployment is given on the left-hand-side, whereas the flow out of unemployment is given on the right-hand-side.

This completes the description of the model when high-skill workers are willing to accept low-tech jobs. Although the model may look complex, it is really rather simple. Firms have only two decisions to make: whether to enter and which type of technology to adopt. Low-tech workers simply search until finding a low-tech firm with a vacancy; whereas high-tech workers need to decide whether to accept low-tech jobs. Wages are negotiated at the time that the match occurs and jobs are destroyed randomly. Expected profits for the firms are given by (1)-(4), wages are given by (5)-(6), and the free entry conditions in (7)-(8) determine the measures of firms that enter. For the workers, expected lifetime income for different labor market states are determined by (8)-(11) and the steady-state conditions which ensure that employment is stable over time are given in (13)-(14). Finally, (12) ensures that high-skill workers make the right decision about accepting low-tech jobs.

Our next goal is to describe how the model would be altered in an EPS equilibrium. Since high-skill workers would be unwilling to accept low-tech jobs, (2), (6) and (11) would not apply. In addition, (3), (9) and (14) would have to be rewritten to take into account the fact that low-tech firms would only be able to hire low-skill workers. These equations would become:

$$
\begin{aligned}
& \text { (3') } \quad r V_{L}=-c+z(\theta) \gamma\left\{J_{L}-V_{L}\right\} \\
& \text { (9') } r U_{H}=b_{N}+m(\theta)(1-\phi)\left[W_{H}-U_{H}\right]
\end{aligned}
$$




$$
\delta E_{H}=\left(1-q-E_{H}\right)(1-\phi) m(\theta)
$$

Such an equilibrium exists if (12) fails to hold when evaluated in equilibrium.

There are two key features that determine when CSM and EPS equilibria exist. First, a CSM equilibrium will not exist if low-tech firms cannot afford to pay high-skill workers enough to convince them to stop searching for a high-tech job. This will occur if the revenue generated by a low-tech firm that matches with a high-skill worker differs significantly from the revenue generated by a high-tech job. The second important factor is expectations; and it is this factor that makes it possible to have CSM and EPS equilibria both exist for the same underlying parameters. To see this, note that if high skill workers are willing to match with low-tech firms, then the value from creating a low-tech vacancy will be high and a large measure of such vacancies will be created. This would make it hard for high-skill workers to find high-tech jobs, making them more willing to match with low-tech firms. Thus, there are some situations in which self-fulfilling expectations can support equilibria of each type for a fixed set of parameters. And, when they do co-exist, the main difference between the two equilibria rests with the technology choices made by firms. The EPS equilibrium is characterized by a greater fraction of the firms adopting the modern technology. This implies that high-skill workers typically prefer the EPS equilibrium, whereas low-skill workers are typically better-off in the CSM equilibrium.

In terms of social welfare, as is well known, equilibria in search models are generally not efficient since decisions made by agents generate external effects. This is the case here as well. For example, the entry and technology decisions made by firms alter the match probabilities for other firms and workers. One way to correct for these external effects is to alter the wage setting mechanisms so that workers are paid their true dynamic marginal products (see Hosios 1990 for details). Since this issue has received ample attention in the literature, we will not deal with it in 
this paper. Instead, we focus on a welfare comparison of the CSM and EPS equilibria when they co-exist.

Since high-skill workers are more productive when using the modern technology, the natural presumption would be that the EPS equilibrium generates greater aggregate income than the CSM equilibrium. However, since high-skill workers typically search longer in the EPS equilibrium (since they reject all low-tech job offers), the EPS equilibrium is characterized by higher unemployment than the CSM equilibrium. Moreover, since the high-skill workers' search decisions are generally sub-optimal, it is possible for the CSM equilibrium to be the preferred outcome. For our purposes, the more interesting case is the one in which the natural presumption is accurate. Thus, for the remainder of the paper we focus on the case in which the EPS outcome yields higher aggregate income than the CSM outcome. We also assume that in the absence of outsourcing, the optimism of high-skill workers is sufficient to make the EPS equilibrium the initial outcome.

\section{The Model with Outsourcing}

In the previous section we implicitly assumed that the cost of establishing and maintaining vacancies by Northern high-tech firms in the South was very high. One effect of globalization is that it becomes cheaper for firms to post vacancies abroad and outsource parts of the production process. In this section, we describe how our model works when Northern hightech firms are able to post vacancies in the South and hire Southern high-skilled workers to produce their output. This requires us to now provide the details of Southern economy.

As noted in the previous section, the Southern economy is quite similar to the Northern economy. The main differences are that the workforce is, on average, more productive in the North and that Southern firms do not have access to the modern technology. Since all active Southern firms must use the basic technology, this implies that before outsourcing becomes 
possible, all Southern workers hold low-tech jobs and receive the same wages. Southern firms enter until the expected profit from posting a low-tech vacancy is zero.

Once outsourcing is a viable option, Northern high-tech firms must decide whether to post a vacancy in the North or the South. If they post a vacancy in the South, they must go through the same type of search process that they would face in the North. For simplicity, we assume that the matching functions in the South and North are identical. Southern workers are assumed to be less productive than their counterparts in the North, and high-skill Southern workers employed by Northern high-tech firms are assumed to be more productive than they would be if employed by a low-tech firm. To be precise, if we let $y_{L S}$ denote the output produced by any Southern worker employed by a low-tech firm and let $y_{H S}$ denote the output produced by a high-skill Southern worker employed by a Northern high-tech firm, the we have $y_{H}>y_{H S}>y_{L}>y_{L S}$. Since we are interested in the impact of high-tech outsourcing, we assume that $y_{L S}$ is low enough that it is never profitable for Northern low-tech firm to outsource production.

The value functions for Northern high-tech firms that outsource production are given by

$$
\begin{aligned}
& r V_{H S}=-c^{*}+z\left(\theta_{S}\right)\left(1-\gamma_{S}\right)\left[J_{H S}-V_{H S}\right] \\
& r J_{H S}=\left\{y_{H S}-w_{H S}-c^{*}\right\}-\delta\left[J_{H S}-V_{H S}\right]
\end{aligned}
$$

where $c^{*}>c$ is the cost of posting and maintaining a vacancy in the South, $J_{H S}$ is the value for an active Northern high-tech firm that has filled its vacancy with a Southern high-skill worker, $V_{H S}$ is the value for an unmatched Northern high-tech firm that has outsourced production, $w_{H S}$ is the wage paid to Southern high-skill workers employed by Northern high-tech firms, $\theta_{S}$ is the measure of labor market tightness in the South, and $\gamma_{S}$ is the fraction of low-skill workers in the 
pool of unemployment in the South. The logic behind (15)-(16) is identical to that given for (1)(4).

For simplicity, we assume that when outsourcing becomes viable for Northern firms, high-skill Southern workers stop accepting low-tech jobs. Thus, the South moves to an EPS equilibrium (the analysis is slightly more complicated but the qualitative results are unchanged if the Southern labor market exhibits cross-skill-matching). This implies that the value functions for Southern firms are given by

$$
\begin{aligned}
& r V_{L S}=-c+z\left(\theta_{S}\right) \gamma_{S}\left[J_{L S}-V_{L S}\right] \\
& r J_{L S}=\left\{y_{L S}-w_{L S}-c\right\}-\delta\left[J_{L S}-V_{L S}\right]
\end{aligned}
$$

where $c$ is the cost to a Southern firm of posting and maintaining a low-tech vacancy, $J_{L S}$ is the value for an active low-tech Southern firm, $V_{L S}$ is the value for an unmatched low-tech Southern firm, and $w_{L S}$ is the wage that Southern firms pay their low-skill workers.

As in the North, Southern wages are negotiated with their values given by the Generalized Nash Bargaining Solution. Thus, if we use $U_{i S}$ to denote the expected lifetime income of an unemployed type $i$ Southern worker (for $i=L, H$ ) then $w_{H S}$ and $w_{L S}$ satisfy

$$
\begin{aligned}
& w_{H S}=\beta\left(y_{H S}-c^{*}\right)+(1-\beta) r U_{H S} \\
& w_{L S}=\beta\left(y_{L S}-c\right)+(1-\beta) r U_{L S}
\end{aligned}
$$

As for Southern workers, their value functions are given by

$$
\begin{aligned}
& r U_{L S}=b_{S}+\phi_{S} m\left(\theta_{S}\right)\left[W_{L S}-U_{L S}\right] \\
& r U_{H S}=b_{S}+\left(1-\phi_{S}\right) m\left(\theta_{S}\right)\left[W_{H S}-U_{H S}\right] \\
& r W_{i S}=w_{i S}-\delta\left(W_{i S}-U_{i S}\right)
\end{aligned}
$$


where $W_{i S}$ denotes the value function for a type $i$ Southern worker employed in a type $i$ job (for $i=L, H), \quad b_{S}$ denotes unemployment benefits in the South and $\phi_{S}$ denotes the proportion of vacancies in the South that are posted by low-tech firms. The logic for (21)-(23) is the same as that given for (8)-(11) above.

Finally, we turn to the steady-state and equilibrium conditions for the South. For employment to remain stable over time, the flows into and out of employment must be equal for both types of workers. Thus, we must have

$$
\begin{aligned}
& \delta E_{L S}=\left(q_{S}-E_{L S}\right) \phi_{S} m\left(\theta_{S}\right) \\
& \delta E_{H S}=\left(1-q_{S}-E_{H S}\right)\left(1-\phi_{S}\right) m\left(\theta_{S}\right)
\end{aligned}
$$

where $E_{i S}$ denotes the measure of employment for type $i$ Southern workers (for $i=L, H$ ). In equilibrium, all agents must be behaving optimally. High-skill Southern workers are behaving optimally when they reject low-tech-jobs if

$$
y_{L S}-c-r U_{H S}<0 \text {. }
$$

This completes the description of the Southern economy when outsourcing is a viable option for high-tech Northern firms. In the next section, we describe the short and long run adjustment of the North when globalization results in high-tech outsourcing.

\section{Adjusting to Globalization}

In this section, we assume that $c^{*}$ is initially too high to justify outsourcing by high-tech Northern firms. Therefore, these firms hire only Northern workers. Northern high-skill workers, optimistic about the prospect of finding high-tech jobs, refuse to accept low-tech jobs and this decision results in the economy settling down in an EPS equilibrium. Globalization then causes $c^{*}$ to fall, making outsourcing an attractive option. Our goal is to describe how the Northern 
economy adjusts in the short-run, when new firms cannot enter the market, and the long-run, when free entry drives the expected return from posting a vacancy back down to zero.

If $c^{*}$ falls enough that $V_{H S}$ becomes positive, unmatched Northern high-tech firms start posting vacancies in the South. Northern high-tech firms that are already producing must compare $J_{H}$, the value of continuing to produce using their Northern workers, and $V_{H S}$, the value obtained if the firm lays off its current employee and posts a vacancy in the South. If $J_{H}>V_{H S}$, the firm continues to produce in the North; whereas, if $J_{H}<V_{H S}$ it lays off its worker and outsources production immediately.

As Northern firms start to outsource, the demand for high-skill Southern workers starts to rise, pushing up $w_{H S}$. For simplicity, we assume that this increase in the wage is sufficient to cause Southern high-skill workers to start rejecting low-tech jobs. In the North, as high-tech firms start shifting production to the South, the demand for high-skill labor falls causing $w_{H}$ to fall. As this wage falls, dislocated workers in the North start accepting low-tech jobs - that is, the EPS equilibrium is destroyed. For the high-tech firms, the increase in $w_{H S}$ causes $V_{H S}$ to fall, whereas the reduction in $w_{H}$ causes $V_{H}$ to rise. A short-run equilibrium is established when Northern high-tech firms are indifferent between posting vacancies in the North and South; that is, when $V_{H}=V_{H S}$. Note that since $V_{H S}=0$ in the initial equilibrium and $V_{H S}$ increases in the short-run, outsourcing leads to positive profits for Northern high-tech firms.

Turn next to the impact of globalization on Northern low-skill workers and low-tech firms. As high-skill workers become dislocated, unemployment increases (altering $\theta$, our measure of labor market tightness). Moreover, as high-tech workers start accepting low-tech jobs, low-skill workers face increased competition for employment. Both of these factors cause $w_{L}$ to fall, harming Northern low-skill workers. This reduction in the low-skill wage and the 
fact that high-skill workers are now willing to work for low-tech firms, implies that Northern low-tech firms benefit and start to earn positive profits.

In summary, the short run impact of high-tech outsourcing is not all that different from the view commonly held in public arenas. High-skill workers become dislocated, see their bargaining power and wages eroded, and start to accept jobs for which they are over-qualified. Low-skill workers are crowded out of the labor market as high-skill workers start competing with them for low-tech jobs. Thus, low-skill workers suffer wage losses as well. The big winners are the firms that all start to earn positive profits due to the reductions in wages and increased availability of workers.

These positive profits trigger entry by new firms in the long-run, with the proportion of new firms that choose to adopt the high-tech technology depending upon the expectations of high-skill workers. Based on their most recent labor market experiences, it seems reasonable to assume that high-skill workers will continue to expect high-tech jobs to be difficult to acquire. As a result, the Northern economy will remain in a CSM equilibrium, with the bulk of new firms that seek to hire Northern workers adopting the basic technology. ${ }^{4}$ In fact, since the world price has not changed, entry by firms will continue until the North reaches the original (preoutsourcing) CSM equilibrium.

The entry by new firms that employ Northern workers pushes Northern wages back up towards their old levels. However, since the new long-run equilibrium is identical to the original CSM equilibrium, we know that high-skill workers suffer long-run wage losses while low-skill workers benefit. That is, in the long-run, outsourcing benefits low-skill workers at the expense of their high-skill counterparts. Given our assumption that aggregate income in the initial

\footnotetext{
${ }^{4}$ A fraction of new high-tech entrants outsource production to the South. However, these firms do not hire Northern workers and therefore their entry has no impact on Northern wages.
} 
situation was higher in the EPS equilibrium, the total gains by the low-skill workers must be smaller than the total losses suffered by the high-skill workers, so that social welfare declines.

We close this section by providing a simple example to illustrate the short and long run effects of outsourcing described above. We follow the search literature in assuming that firms and workers have equal bargaining power $(\beta=.5)$ and that the matching function is CobbDouglass $m(u, v)=2 \sqrt{u v}$. As for the parameters, we assume that: jobs last, on average, 5 years so that $\delta=.2$; agents discount the future a rate such that $r=.05 ; c$, the cost of creating a vacancy in the North is given by .1; and that $b_{i}, i=N, S$, unemployment benefits are equal to .5 and .3 correspondingly. As we will see below, this assumption about unemployment benefits implies a replacement rate in the North of about $30 \%$, which is in line with most estimates of the effective replacement rate in the US (see, for example, Millard and Mortensen 1997). The Northern economy is characterized by $y_{H}=1.8, y_{L}=1.6$, and $q_{N}=.6$, so that $40 \%$ of the Northern labor force is highly-skilled. In the South, we have $y_{H S}=1.7, y_{L S}=.6$, and $q_{S}=.8$.

It is straightforward to check that these parameter values satisfy all of our assumptions and guarantee that in the initial, pre-globalization Northern economy both EPS and CSM equilibria exist. We assume that the North starts out in the EPS equilibria. The EPS equilibrium wages are $w_{H}=1.611$ and $w_{L}=1.433$. Social welfare, which we define as the sum of expected lifetime income across all Northern workers is given by

$$
\Omega_{N}^{E P S}=E_{L} W_{L}+E_{H} W_{H}+\left(q_{N}-E_{L}\right) U_{L}+\left(1-q_{N}-E_{H}\right) U_{H},
$$

which, in this case, is equal to 28.855 . In this initial equilibrium, $57 \%$ of the firms that enter choose to adopt the basic technology.

Now, suppose that $c^{*}$, the cost to a Northern high-tech firm of posting a vacancy in the South, falls from some initial high level down to .2. At this value for $c^{*}$, it is now profitable for 
some high-tech firms to outsource. As they do so, the deterioration of high-tech job prospects forces high-skill workers in the North to start accepting low-tech jobs. That is, the EPS equilibrium is destroyed and the economy moves to a short-run CSM equilibrium. Calculating the short-run equilibrium is difficult, since it requires workers to forecast future entry and take this into consideration when negotiating wages with the firms. ${ }^{5}$ However, we can obtain a backof-the-envelope calculation if we assume that there is no future entry. This assumption would overstate the bargaining power of firms, therefore overstating the losses that workers are likely to suffer. Given that caveat, our numeric analysis (assuming no entry) suggests that the short-run equilibrium is reached when roughly $32 \%$ of the Northern high-tech firms outsource production. As we discussed above, both types of Northern workers are harmed by this. Indeed, the wage earned by an average highs-kill worker falls from 1.611 to 1.030 , whereas low-skill workers see their wages drop from 1.433 to 0.668 .

Assuming that the economy remains in a CSM equilibrium, the short-run profits earned by firms leads to significant entry in the long run, with the measure of low-tech firms increasing by roughly $30 \%$. These new low-tech entrants take advantage of the fact that high-skill workers now accept low-tech vacancies. When the Northern economy reaches its new long-run equilibrium, low-skill workers find that there wages have increased to a value above what the earned in the initial EPS equilibrium (from 1.433 to 1.45 ), whereas the high-skill workers suffer permanent wages losses (their wage drops from an initial value of 1.611 to an average of 1.512 ). Aggregating expected lifetime income across workers gives social welfare in a CSM equilibrium, which is given by

$$
\Omega_{N}^{C S M}=E_{L} W_{L}+E_{H}\left[\phi W_{U}+(1-\phi) W_{H}\right]+\left(q_{N}-E_{L}\right) U_{L}+\left(1-q_{N}-E_{H}\right) U_{H} .
$$

\footnotetext{
${ }^{5}$ The main difficulty caused by this is that the model would be characterized by non-stationary value functions.
} 
In our example, $\Omega_{N}^{C S M}=28.753$, so that globalization reduces welfare. This reduction in welfare is a direct result of the impact of globalization on the labor market expectations of high-skill workers in the North.

\section{Discussion}

The primary policy instrument used to compensate dislocated workers in the US is unemployment insurance (through TAA). Because this policy discourages workers from finding new jobs quickly (by effectively rewarding them for remaining unemployed) it has been widely criticized as inefficient and many in the policy community have suggested replacing it with a wage subsidy program (see, for example, Parsons 2000, Kletzer and Litan (2001), and Hufbauer and Goodrich 2001). In our model, the disincentive effects of TAA that seem troubling in other contexts, make unemployment insurance a relatively good way to compensate displaced workers. To see this, note that an increase in the unemployment benefit $(b)$ results in an increase in $U_{H}$, which makes it easier to support the EPS equilibrium. ${ }^{6}$ Thus, the government can keep the economy from moving to a CSM equilibrium in the short run by increasing the unemployment benefits offered to high-skill workers dislocated by outsourcing. These extra benefits could then be phased out in the long-run. This follows from the fact that if high-skill workers do not change their expectations, entry by new high-tech firms will restore the initial EPS equilibrium in the long run.

In closing, it is worth emphasizing that our focus in this paper has been rather narrow. We have restricted attention to one aspect of globalization, the outsourcing of high-skill jobs. In particular, we have assumed away one of the main benefits of globalization, exploiting an economy's comparative advantage. It should be clear, however, that we could easily embed the

\footnotetext{
${ }^{6}$ The EPS equilibrium exists when (12) does not hold. Increasing $U_{H}$ makes this more likely.
} 
economy studied in this paper in a simple general equilibrium model. We could expand our concept of globalization by assuming an initial protective tariff that is reduced at the same time that the cost of outsourcing falls. One of our main results would still go through in that the difference between high and low-skill wages would decrease. However, distributional effects caused by a change in relative price could mitigate the potential increase in the wage earned by low-skill workers. This would be the case if, for example, the import-competing sector is also the sector for which outsourcing is an issue and if labor is specific to this sector.

We have also assumed that the types of production technologies used by firms are fixed. Our objective was to show that in this case low-skill workers may become better-off if high-tech jobs are outsourced to low-cost labor markets. In reality, firms that enjoy high temporary profits do not rest on their laurels. Demand by consumers for new commodities and product market competition between firms often force managers to reinvest their short-run profits in an attempt to develop new products, find new and better technologies, and start new businesses. All of these actions create new jobs and these activities are likely to take place in countries where the labor force is relatively more productive. As a result, workers face increased incentives to accumulate human capital. In such a setting, the impact of outsourcing on the development and adoption of new technologies can be ambiguous. It should depend on expectations of firms about the future distribution of skills in different countries and the expectations of workers about the availability of high-tech jobs (which would determine their willingness to investment in human capital). For now, we leave this as a topic for future research. 


\section{References}

Albrecht, James and Susan Vroman (2002). A matching model with endogenous skill requirements. International Economics Review 43(1): 282-305.

Antràs, Pol and Elhanan Helpman (2004). Global Sourcing. C.E.P.R. Discussion Paper 4170.

Bhagwati, Jagdish, Arvind Panagariya, and T.N. Srinivasan (2004). The muddles over outsourcing. Journal of Economic Perspectives 18(4): 93-114.

Grossman, Gene M. and Elhanan Helpman (2002). Integration vs. outsourcing in industry equilibrium. Quarterly Journal of Economics 117:1: 85-120.

Davidson, Carl and Steven J. Matusz (2006). Trade liberalization and compensation. International Economic Review (forthcoming).

Davidson, Carl, Steven J. Matusz, and Andrei Shevchenko (2005). Globalization and firm level adjustment with imperfect labor markets. Michigan State University Working Paper.

Doms, Mark; Timothy Dunne; and Kenneth Troske (1997). Wages, workers, and technology. Quarterly Journal of Economics 112(1): 252-90.

Hosios, Arthur (1990). On the efficiency of matching and related models of search and unemployment, Review of Economic Studies, 57(2): 279-98.

Hufbauer, Gary and Ben Goodrich (2001). Steel: Big problems, better solutions. Policy Brief. Washington D.C.: Institute for International Economics.

Jacobson, Louis, Robert LaLonde, and Daniel Sullivan (1993). Earnings losses of displaced workers. American Economic Review, 83: 685-709.

Kletzer, Lori (2001). What are the Costs of Job Loss from Import-Competing Industries? Washington D.C.: Institute for International Economics.

Kletzer, Lori and Robert Litan (2001). A prescription to relieve worker anxiety. Policy Brief No. 73. Washington D.C.: Brookings Institution. 
Millard, Stephen and Dale Mortensen (1997). The unemployment and welfare effects of labor market policy: A comparison of the USA and the UK. in D. J. Snower and G. de la Dehesa (eds.) Unemployment Policy: Government Options for the Labor Market, Cambridge University Press, Cambridge.

Mortensen, Dale and Christopher Pissarides (1994). Job creation and job destruction in the theory of unemployment. Review of Economic Studies 61: 397-415.

Pissarides, Christopher (2000). Equilibrium Unemployment Theory (2 ${ }^{\text {nd }}$ edition), Cambridge, MA, MIT Press.

Parsons, Donald (2000). "Wage Insurance: A Policy Review." Research in Employment Policy, 2: 119-140.

Slaughter, Matthew (2004). Globalization and employment by U.S. multinationals: A framework and facts. Dartmouth College Working Paper, available at http://mba.tuck.dartmouth.edu/pages/faculty/matthew.slaughter/MNE\%20Outsourcing\%2 00304.pdf

Yeaple, Stephen (2005). A simple model of firm heterogeneity, international trade and wages. Journal of International Economics 65(1): 1-20. 